\title{
Bone marrow-derived cells in ocular neovascularization: contribution and mechanisms
}

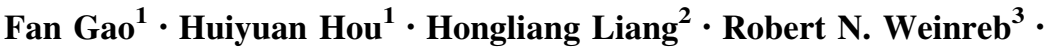 \\ Haiyan Wang ${ }^{1} \cdot$ Yusheng Wang ${ }^{1}$
}

Received: 27 December 2015/Accepted: 2 February 2016/Published online: 15 February 2016

(c) The Author(s) 2016. This article is published with open access at Springerlink.com

\begin{abstract}
Ocular neovascularization often leads to severe vision loss. The role of bone marrow-derived cells (BMCs) in the development of ocular neovascularization, and its significance, is increasingly being recognized. In this review, we discuss their contribution and the potential mechanisms that mediate the effect of BMCs on the progression of ocular neovascularization. The sequence of events by which BMCs participate in ocular neovascularization can be roughly divided into four phases, i.e., mobilization, migration, adhesion and differentiation. This process is delicately regulated and liable to be affected by multiple factors. Cytokines such as vascular endothelial growth factor, granulocyte colony-stimulating factor and erythropoietin are involved in the mobilization of BMCs. Studies have also demonstrated a key role of cytokines such as stromal cell-derived factor-1, tumor necrosis factor- $\alpha$, as well as vascular endothelial growth factor, in regulating the migration of BMCs. The adhesion of BMCs
\end{abstract}

Fan Gao and Huiyuan Hou have contributed equally to this work and should be regarded as co-first authors.

Huiyuan Hou

hhywyyx@163.com

Yusheng Wang

wangys003@126.com

1 Department of Ophthalmology, Eye Institute of Chinese PLA, Xijing Hospital, Fourth Military Medical University, No. 127, Changle West Road, Xi' an, China

2 Department of Cardiovascular Surgery, Institute of Cardiovascular Disease of Chinese PLA, Xijing Hospital, Fourth Military Medical University, Xi' an 710032, Shaanxi Province, People's Republic of China

3 Department of Ophthalmology, University of California, San Diego, La Jolla, CA, USA is mainly regulated by vascular cell adhesion molecule-1, intercellular adhesion molecule- 1 and vascular endothelial cadherin. However, the mechanisms regulating the differentiation of BMCs are largely unknown at present. In addition, BMCs secrete cytokines that interact with the microenvironment of ocular neovascularization; their contribution to ocular neovascularization, especially choroidal neovascularization, can be aggravated by several risk factors. An extensive regulatory network is thought to modulate the role of BMCs in the development of ocular neovascularization. A comprehensive understanding of the involved mechanisms will help in the development of novel therapeutic strategies related to BMCs. In this review, we have limited the discussion to the recent progress in this field, especially the research conducted at our laboratory.

Keywords Bone marrow-derived cells $\cdot$ Stem cells . Ocular neovascularization $\cdot$ Mechanism

$\begin{array}{ll}\text { Abbreviations } \\ \text { AMD } & \text { Age-related macular degeneration } \\ \text { bFGF } & \text { Basic fibroblast cell growth factor } \\ \text { BM } & \text { Bone marrow } \\ \text { BMCs } & \text { Bone marrow-derived cells } \\ \text { CNV } & \text { Choroidal neovascularization } \\ \text { CV } & \text { Corneal neovascularization } \\ \text { DR } & \text { Diabetic retinopathy } \\ \text { ECs } & \text { Endothelial cells } \\ \text { ECM } & \text { Extracellular matrix } \\ \text { eNOS } & \text { Endothelial nitric oxide synthase } \\ \text { EPCs } & \text { Endothelial progenitor cells } \\ \text { EPO } & \text { Erythropoietin } \\ \text { G-CSF } & \text { Granulocyte colony-stimulating factor }\end{array}$




$\begin{array}{ll}\text { GM-CSF } & \begin{array}{l}\text { Granulocyte macrophage colony- } \\ \text { stimulating factor }\end{array} \\ \text { HSCs } & \text { Hematopoietic stem cells } \\ \text { ICAM-1 } & \text { Intercellular adhesion molecule-1 } \\ \text { miRNA } & \text { MicroRNAs } \\ \text { MMP-9 } & \text { Matrix metalloproteinase-9 } \\ \text { MSCs } & \text { Mesenchymal stem cells } \\ \text { OIR } & \text { Oxygen-induced retinopathy } \\ \text { PAI-1 } & \text { Plasminogen activator inhibitor } \\ \text { PEDF } & \text { Pigment epithelium-derived factor } \\ \text { RBP-J } & \text { Recombination signal-binding protein JK } \\ \text { RNV } & \text { Retinal neovascularization } \\ \text { RPE } & \text { Retinal pigment epithelial } \\ \text { SDF-1 } & \text { Stromal-derived factor-1 } \\ \text { TNF- } \alpha & \text { Tumor necrosis factor- } \alpha \\ \text { VCAM-1 } & \text { Vascular cell adhesion molecule-1 } \\ \text { VE-cadherin } & \text { Vascular endothelial cadherin } \\ \text { VSMCs } & \text { Vascular smooth muscle cells }\end{array}$

\section{Introduction}

Ocular neovascularization (NV) can occur in multiple ocular compartments, including in cornea, iris, retina, optical disc and choroid. It often leads to intractable and severe vision loss [1-3]. These new vessels have abnormal cellular components, are structurally fragile and prone to hemorrhage. The resultant hemorrhage often causes accumulation of blood in the anterior chamber and vitreous which reduces visual acuity. Moreover, the resultant edema, exudates and accompanying fibrosis may impair vision by several mechanisms including reduced corneal transparency and increased intraocular pressure that may result in structural and functional impairment of retinal neurons [3].

For years, it had been demonstrated that in addition to cells in situ, bone marrow-derived cells (BMCs) contribute to the formation of ocular neovascularization [4]. Hence, a better understanding of BMCs' contribution to ocular neovascularization is important to the development of new therapeutic targets and strategies. The steps and mechanisms involved in BMCs' contribution to ocular neovascularization are complex and involve multiple regulating factors, cells and pathways. We review the main mechanisms that are known to modulate the role of BMCs in ocular neovascularization, especially in corneal neovascularization $(\mathrm{CV})$, retinal neovascularization (RNV) and choroidal neovascularization (CNV), and discuss the risk factors affecting the contribution of BMCs.

\section{Bone marrow-derived cells and ocular neovascularization}

Neovascularization involves two main modalities. During angiogenesis, endothelial cells (ECs) sprout from adjacent blood vessels. With vasculogenesis, cells from circulation form blood vessels [5]. Ocular neovascularization involves both modalities, and the available evidence implicates a variety of BMCs in the pathogenesis of ocular neovascularization $[6,7]$.

The participation and differentiation of BMCs in neovascularization in cornea, retina and choroid has been widely studied. BMCs consist of various types of stem cells as well as circulating mononuclear macrophages [7, 8]. Recent studies suggest an important role for endothelial progenitor cells (EPCs), hematopoietic stem cells (HSCs) and mesenchymal stem cells (MSCs) in ocular neovascularization [4]. These stem cells have been shown to differentiate into different several cell types, including vascular components (vascular ECs, vascular smooth muscle cells (VSMCs), and pericytes) and extravascular cells (myofibroblasts, inflammatory cells, retinal pigment epithelial (RPE) cells and glial cells) [1]. In addition to stem cells, bone marrow (BM)-derived macrophages are key modulators of the severity of ocular neovascularization. As an example, after entering the area of neovascularization, macrophages secrete angiogenic factors and stimulate expression of stromal-derived factor-1 (SDF-1) in RPE cells, which is associated with migration and adhesion of BMCs into ischemic or injured tissue [8].

\section{Bone marrow-derived cells and corneal neovascularization}

Several inflammatory disease states including infectious diseases and trauma are known to be associated with $\mathrm{CV}$ [9]. CV can be artificially induced in animal models by different approaches as an aid to investigate mechanisms of not only corneal pathology but also of general angiogenesis [10]. In a rat model of suture-induced inflammatory CV, the CD11b-positive myeloid cells appeared to pre-pattern the extracellular matrix (ECM), direct the growth of sprouts, and incorporate into the sprout tip endothelium, indicating BMCs' participation in inflammatory CV [11]. Moreover, implantation of a Hydron pellet containing basic fibroblast cell growth factor (bFGF), in the absence of substantial inflammation, was shown to induce CV. Pericytes involved in this model of $\mathrm{CV}$ had a dual source, i.e., $\mathrm{BM}$ and preexisting limbus capillaries, whereas ECs only originated from preexisting capillaries. At sites of $\mathrm{CV}$, $>90 \%$ of BM-derived pericytes were shown to express 
CD45 and CD11b, respectively, which indicates their hematopoietic origin from the BM, and their contribution in causing CV [6]. This finding was further supported by other studies that employed various factors for inducing $\mathrm{CV}$ via mobilization, migration and incorporation of BMderived EPCs such as VEGF [12], granulocyte macrophage colony-stimulating factor (GM-CSF) [13], secretoneurin [14] and peroxisome proliferator-activated receptor- $\delta$ [15].

\section{Bone marrow-derived cells and retinal neovascularization}

Retinal neovascularization is the main complication of proliferative vascular diseases, such as diabetic retinopathy (DR) and retinopathy of prematurity. Some common themes have been identified in different disease states. Retinal ischemia/insult is a key feature of RNV, as is the involvement of BMCs [16]. A study by Grant et al. [17] indicated that BM-derived HSCs can differentiate into all hematopoietic cell lineages involved in the pathogenesis of RNV. They also found the recruitment of EPCs at the sites of ischemic lesion [17]. Another study confirmed the involvement of BMCs, which had the characteristic elongated appearance of EC, incorporated into forming RNV by selectively targeting retinal astrocytes [18]. This finding is supported by the results of several other studies that showed the contribution of BMCs in laser injury-associated model and oxygen-induced retinopathy (OIR) model [1925].

The involvement of BMCs has also been confirmed clinically. In surgically excised epiretinal membranes from patients with proliferative DR, the presence of BM-derived $\mathrm{CD}_{133^{+}}$EPCs and CD14 ${ }^{+}$monocytes has been documented, which further implicates BMCs are involved in retinal angiogenic diseases [26].

\section{Bone marrow-derived cells and choroidal neovascularization}

Choroidal neovascularization represents the final pathway leading to severe visual loss in approximately 40 ocular diseases, of which the most common is age-related macular degeneration (AMD) [16]. Mounting evidence indicates the involvement of BMCs in CNV, both in clinical specimens and in animal models. In patients with AMD, AC133 positive cells, a putative marker of EPCs and HSCs, were detected in surgically excised CNV specimens. Immunoreactivity showed that the AC133-positive cells in the avascular fibrous stromal core were RPE cells and macrophages, and those in the highly vascular peripheral were ECs [27]. In addition, a series of clinical studies conducted in Japan indicated a correlation of circulating HSCs with neovascular AMD, idiopathic CNV and pathologic myopia [28-30]. The involvement of BMCs has also been confirmed in animal models of CNV. EspinosaHeidmann et al. [31] were the first to report the role of BMCs in CNV in the year 2003. This was further supported by several others that showed that the recruitment of BMCs was associated with the severity of $\mathrm{CNV}$ and that targeting homing and adhesion of BMCs using antibody treatment may prevent CNV [32-34]. In a laser-induced mice model of CNV, we observed differentiation of BMCs into parts of vascular structure and surrounding sprouts, thus further implicating BMCs in the pathogenesis of CNV [7].

\section{Proportions and time frame of bone marrow- derived cells' contribution to ocular neovascularization}

In different kinds of ocular neovascularization, proportions of BMCs in the cellular vasculature are diverse. Only $17.7 \%$ of vascular ECs and $53 \%$ of pericytes were shown to originate from $\mathrm{BM}$ in $\mathrm{CV}$, whereas in $\mathrm{CNV}$, the proportion of BM-derived vascular ECs was approximately $50-60 \%[6,35]$. In mice treated with both transplantation of green fluorescent protein-labeled BM and laser-induced $\mathrm{CNV}$, the percentage of BMCs in CNV may be even greater and more stable if the documented repopulation with transplanted stem cells is $>90 \%$ because of the link between the percentage of BMCs in $\mathrm{CNV}$ and the repopulation in chimeric mice [31].

The time frame of BMCs' contribution to ocular neovascularization remains understudied. It is believed that BMCs arrive at the site of ocular neovascularization at the initiation of neovascularization. In inflammatory CV, BMderived myeloid cells were shown to form endotheliumfree tunnel in response to inflammatory stimuli in the initial hours after induction; their peak levels were observed at day 1 [11]. In a mice model of CNV, the presence of BMCs was demonstrated in the lesions as early as day 3 after laser treatment. Further, using bioluminescence imaging the dynamic conduct of BMCs in CNV has been observed. The number of BMCs appeared to peak at day 7 after treatment with the numbers showing a decline from the day 14 onwards and remained stable from day 28 [7]. In addition, the continuous presence of macrophages was shown in lesions of CNV and other areas of the eye from day 7 after laser treatment [36]. However, the time frame of BMCs in RNV remains unclear and requires further investigation. 


\section{Molecular mechanisms of bone marrow-derived cells' contribution to ocular neovascularization}

Although BMCs in ocular neovascularization mentioned above are different in several respects (such as their proportions, time frame of BMCs' contribution), they also share some similarities. For example, their participation in the development of ocular neovascularization includes four steps, i.e., mobilization, migration, adhesion and differentiation, and are regulated and affected by multiple factors (Fig. 1).

\section{Mobilization of bone marrow-derived cells from bone marrow to circulation}

On stimulation by injury or drugs, BMCs are mobilized from $\mathrm{BM}$ to circulation to perform several physiological and pathological roles. Both preclinical studies and clinical studies have documented an increasing expression of various cytokines (such as VEGF) occurring in response to local tissue injury, both in circulation and in clinical specimens of ocular neovascularization tissues $[37,38]$. As a result, the BM microenvironment transitions from a quiescent to an activated state, and the mobilization of BMCs occurs secondary to these increased levels, including those of VEGF, granulocyte colony-stimulating factor (G-CSF) and erythropoietin (EPO) levels [4].

VEGF-A, a member of VEGF family, is known to play a crucial role in the development of ocular neovascularization. In CV, the interaction of VEGF-A and VEGF receptor 1 has an immune amplification effect in facilitating neovascularization via recruitment of mononuclear macrophages [39]. Unbalanced expressions of VEGF and pigment epithelium-derived factor (PEDF) are thought to be the primary cause of ocular neovascularization. In addition to its localized angiogenic effects in the neovascular lesions, the synergistic effect of both increased VEGF-A and decreased PEDF may also have a systemic effect that blocks the mobilization of EPCs from BM to attenuate RNV [25]. VEGF, which is secreted from both ocular tissues and BMCs, can of itself contribute to the mobilization of BMCs $[12,40]$.

The endothelial nitric oxide synthase (eNOS) pathway plays a pivotal role in that process with both matrix metalloproteinase-9(MMP-9) and eNOS appearing to be of particular importance. In earlier studies, deletion of these genes was shown to block the mobilization of BMCs from the BM. Further, binding of VEGF to VEGF receptor-2, and that of SDF-1 to CXCR4, appeared to enhance mobilization of BMCs, resulting in the release of MMP-9 through activation of the eNOS pathway, which includes phosphorylation of Akt [12, 41]. Due to the increased
MMP-9, the membrane-bound kit ligand is converted into soluble kit ligand, which weakens the interaction of stromal cell and BMCs, thereby facilitating the mobilization of BMCs from BM to peripheral blood [42].

Cytokines such as G-CSF and GM-CSF are also known to promote mobilization of the BMCs to periphery. More recently, it was shown to play a role both within the cells themselves and in the BM microenvironment, instead of the G-CSF receptors on BMCs. A recent study demonstrated the effect of G-CSF on the expression and function of HSCs surface adhesion molecules in inhibiting apoptosis of HSCs [43]. In addition, G-CSF has also been reported to decrease the expression of vascular cell adhesion molecule1 (VCAM-1) in BM, which in turn stimulates release of MMPs and ECM degeneration. In the context of ocular neovascularization, mobilization of EPCs from BM into the circulation was shown to have occurred in response to GMCSF in enhanced CV [13].

Erythropoietin is a hormone known to stimulate BM erythrocyte production. Increased EPO levels in post-MI heart failure were shown to increase the number of EPCs in the peripheral blood [44]. Further, EPO is also known to facilitate mobilization of BMCs into the circulation to promote ocular neovascularization. Earlier studies conducted on OIR mouse model revealed a suppression of EPO levels in the vessel loss phase. Early use of EPO could protect against hypoxia-induced retinal neuron apoptosis. Conversely, late use of EPO was shown to aggravate pathological neovascularization instead of protecting the retina, which suggests that EPO likely contributes to the mobilization and recruitment of BMCs into retinal neovascular lesions at a time when the angiogenic response has already started [45].

\section{Migration of bone marrow-derived cells from circulation to ocular lesions}

Owing to the chemotactic effect of related cytokines, BMCs can migrate from circulation into the ocular neovascularization lesions. This process is regulated by a complex interplay between multiple pathways, the mechanism of which is not well understood.

In several studies, BMCs have shown significant chemotactic response to several factors in ocular neovascularization. A typical example is MSCs which was shown to readily migrate to neovascular area as against the other normal organs in a study of CNV [46]. In another study of RNV, the targeted migration of BMCs was shown to be related with R-cadherin. The mechanism was similar to that in the migration of endogenous retinal vascular ECs along an astrocytic template using R-cadherin-mediated guidance, during formation of retinal vascular layer and 
Fig. 1 Pathways and mechanisms underlying the contribution of BMCs in the pathogenesis of ocular neovascularization. BMCs contribute to the development of ocular neovascularization in four phases (mobilization, migration, adhesion and differentiation), and this process is finely regulated by complex signaling pathways. Cytokines, such as VEGF and SDF-1, are involved in mobilization and migration; the adhesion of BMCs is mainly regulated by adhesion molecules including VCAM-1 and ICAM-1.

However, the mechanisms regulating the differentiation of BMCs are largely unknown at present. BMCs bone marrowderived cells, $V E G F$ vascular endothelial growth factor, $V E G F R$ VEGF receptor, G-CSF granulocyte colony-stimulating factor, $E P O$ erythropoietin, $H I F-1$ hypoxia-inducible factor1, $S D F-1$ stromal cell-derived factor-1, CXCR4 CXC receptor4, eNOS endothelial nitric oxide synthase, MMPs matrix metalloproteinases, MkitL membrane-bound kit ligand, SkitL soluble kit ligand, EC endothelial cells, VSMCs vascular smooth muscle cells, $M \varphi$ macrophages, Ang II angiotensin II, ICAM-1 intercellular adhesion molecule1, VCAM-1 vascular cell adhesion molecule-1

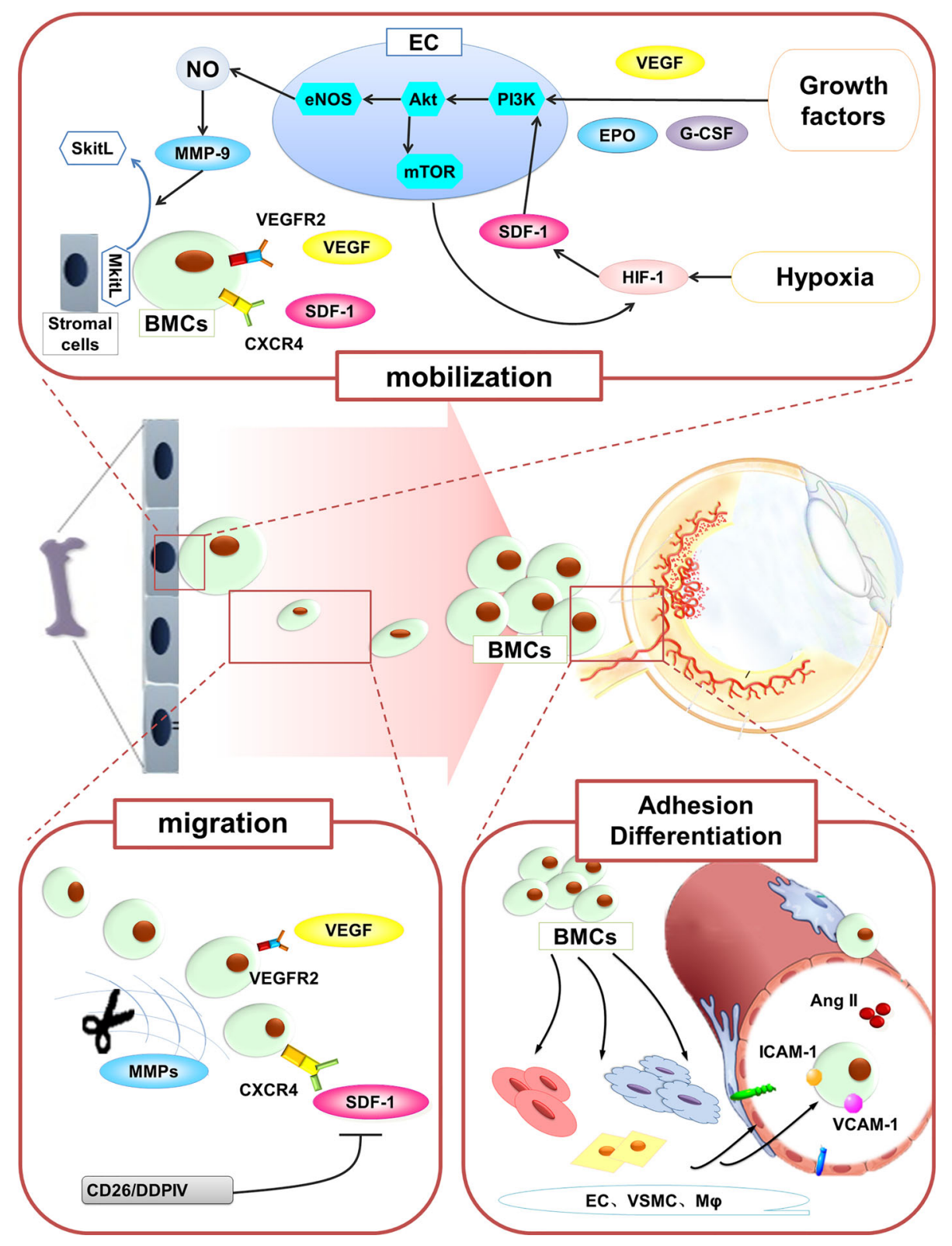

plexuses [47]. Generally, the chemokines and proinflammatory cytokines such as tumor necrosis factor- $\alpha$ (TNF- $\alpha$ ) are the most critical factors in signals of migration.

Chemokines and their receptors play an important role in the selective migration of BMCs. These include SDF-1/ CXCR4 and fractalkine/CX3CR1. Chemokines with chemoattractant properties belong to four families: CXC, $\mathrm{CC}, \mathrm{CX} 3 \mathrm{C}$ and C. SDF-1 is a member of CXC chemokine family and induces migration of BMCs to the target tissues via binding to CXCR4 expressed on various cells like vascular ECs and BMCs [48]. Further, SDF-1/CXCR4 have been implicated in causing the influx of EPCs, HSCs and MSCs in RNV and CNV models, and CXCR4 antagonists have been shown to reduce the influx of these BMCs
[41]. SDF-1 upregulation can be facilitated by the hypoxicinducible factor- $1 \alpha$ in the injured or hypoxic RPE layer, resulting in migration of BMCs to the ocular region [48]. In addition, amyloid $\beta$ in drusen was shown to enhance EPCs migration via upregulation of CX3CR1, a receptor of fractalkine, which is also known to facilitate the development of CNV [49].

Tumor necrosis factor- $\alpha$ was earlier believed to enhance tissue inflammation; however, in a study on CV, absence of TNF- $\alpha$ was shown to augment pathological neovascularization and post-inflammatory scarring instead of ameliorating the same [50]. Another study demonstrated that TNF- $\alpha$ receptor $1 b$, which is selectively expressed on BMderived inflammatory cells, induced signals to upregulate 
inflammatory cell invasion and promote angiogenic response in CNV [51].

In addition to the cytokines mentioned above, ocular tissues stimulated by different factors were also shown to produce enzymes such as MMPs that degenerate ECM, promote sprouting of new blood vessels, and serve to enhance the contribution of BMCs to ocular neovascularization [52].

\section{Adhesion of bone marrow-derived cells in ocular neovascularization}

When BMCs target sites of ocular neovascularization, many cell adhesion molecules, including VCAM-1, intercellular adhesion molecule-1 (ICAM-1) and vascular endothelial cadherin (VE-cadherin), facilitate the process of adhesion. In vivo studies examining the adhesion of BMCs have shown an increased expression of VE-cadherin after EPCs mobilization. Further, with the influx of BMCs in the neovascular area, the VCAM-1 and ICAM-1 expressions on adjacent retinal vessels were also upregulated [21, 23]. These findings are consistent with those from in vitro studies that have demonstrated enhanced adhesion of BMCs to vascular ECs such as VCAM-1/VLA-4 and ICAM-1/ $\beta-2$ integrin interactions after binding of these adhesion molecules to their ligands.

Other in vitro studies have shown the effect of P-selectin and angiotensin II (Ang II) on the adhesive property of BMCs. MSCs bind to ECs in a P-selectin-dependent manner in vitro. However, P-selectin glycoprotein ligand 1 is not expressed by MSCs, and the main selectin ligands on MSCs are yet to be determined [53]. Ang II, an octapeptide hormone, was shown to enhance the BM-derived EPCsmatrix adhesion, which is mediated by NO through upregulation of integrin [54].

\section{Differentiation of bone marrow-derived cells into neovascular cells}

Most of BMCs differentiate into EC, VSMCs and macrophages after arriving at the sites of ocular neovascularization. Some of them have completed differentiation process before permeating through Bruch's membrane, even while still in the choroidal blood vessels. Interestingly, some BMCs were found in cornea, optic disc and iris in the absence of neovascularization; some of them represent arborization shape and have been shown to be F4/80-positive, which suggests that there may be other functions for BMCs in the eye besides its contribution to ocular neovascularization [7].

Different microenvironments induce differentiation of BMCs in several directions, and the mechanism of interaction of BMCs and ocular neovascularization microenvironment needs to be more clearly defined. In the microenvironment of newborn mice retinal neurons, there are cytokines which can induce BMCs differentiation and activate specific signaling pathways. Moreover, in RNV and retinal degenerative disease, BMCs implanted in retinal inferior vena have been shown to differentiate into vascular ECs and photoreceptor cells, and to exert profound vasculotrophic and neurotrophic effects [17, 18, 22, 55]. The differentiation of BMCs in CNV has also been investigated. In vivo studies have shown a concentration of BMCs, most of which are of EPCs phenotype, at the RPE layer with prominent expression of SDF-1 [48]. Moreover, in vitro experiments have shown that higher levels of SDF-1 could induce differentiation of BMCs into ECs (unpublished). Indeed, the SDF-1/CXCR4 signaling pathway may not only contribute to the chemotactic effect, but also may induce BMCs differentiation into $\mathrm{EC}$, which is necessary for the development of ocular neovascularization.

As the ocular neovascularization is developing, the ECs differentiate into tip and stalk cells, a process that is regulated by Notch signaling [56]. Recent studies found that notch signal could not only suppress or stimulate the tip cell formation, but also affect EPCs mobilization, proliferation and differentiation. The role of Notch signaling is complex and varies in different kinds of neovascularization. In some kinds, it stimulates neovascularization, while in some others it suppresses it or causes vascular regression partly via regulating the differentiation and functionality of EPCs [57-59]. In ischemic neovascularization, Jagged-1, one of the Notch ligands, was found to mediate notch signals for stimulating differentiation of EPCs toward the endothelial lineage, which appeared to enhance neovascularization [58]. Another study on a mice model of CNV showed that deficiency of recombination signal-binding protein $\mathrm{J} \kappa(\mathrm{RBP}-\mathrm{J})$, the transcription factor downstream of notch receptors, induces a more intensive angiogenic response to injury and may modulate differentiation of EPCs into circulating ECs. Further, RBP-J deficiency was also shown to induce angiogenesis in retina and cornea, which suggests that the RBP-J-mediated notch signaling may be involved in the maintenance of the vascular homeostasis in eye, partly by affecting EPCs differentiation [59].

\section{Cytokines from bone marrow-derived cells}

BMCs not only take apart in the formation of vascular structure, but are also known to secret multiple kinds of cytokines that effect vascular cells and the surrounding tissues in addition to BMCs themselves, thus regulating the development of ocular neovascularization. VEGF, bFGF, SDF-1, cathepsin L, MMP-13 and plasminogen activator 
inhibitor (PAI-1) are all known to be produced by BMCs $[4,40]$. It is also known that BM-derived MSCs secrete most of the pro-angiogenic factors necessary for ocular neovascularization (such as, VEGF). Under hypoxic conditions, MSCs were shown to migrate into ocular lesions and produce VEGF through paracrine mechanism to stimulate vascular ECs proliferation and further influx of BMCs [46, 60]. Others have also reported that BMCs in CNV lesions are a rich source of VEGF and bFGF [7].

Besides sufficient pro-angiogenic factors, the degradation of basement membranes and extracellular matrix is a precondition for sprouting of vascular cells and the neovascularization. Proteolytic enzymes such as cathepsin cysteine proteases and MMPs are known to induce ocular matrix degradation leading to ocular neovascularization. In both OIR and CNV models, for the most part, cathepsin L in lesions was from EPCs, which are VE-cadherin-positive and have been shown to contribute to ocular neovascularization. Both in wild-type mice with cathepsin L inhibitors and in cathepsin L-deficient mice, a similar decrease in ocular neovascularization has been documented. CNV-related in vitro and in vivo studies have demonstrated that the pro-angiogenic effect of MMP-13 is mainly mediated through BM-derived MSCs. In the event of excessive secretion of MMP-13 by MSCs, the state of hemostasis between stimulatory and inhibitory angiogenic factors may be disrupted, thereby stimulating CNV [52].

Recent studies have revealed that the same cytokines may contribute to neovascularization by different mechanisms, depending upon their origin. For example, PAI-1 derived from BMCs, as against that derived from host ocular cells, plays a crucial role in the development of CNV. Interestingly, a contrasting phenomenon is demonstrable in tumor-related neovascularization in which PAI-1 produced by host cells was shown to play a key role [61].

\section{MicroRNAs in bone marrow-derived cells' contribution to ocular neovascularization}

MicroRNAs (miRNA) are endogenous small (19-22 nucleotides), non-coding RNAs generated by the sequential processing of primary miRNA and Dicer1 in the cytoplasm. Mature miRNAs associate with the $3^{\prime}$ untranslated regions of the specific target $\mathrm{mRNAs}$ to downregulate gene expression by targeting mRNAs for translational suppression or mRNA degradation [62].

Furthermore, recent studies also indicated that miRNAs were shown to regulate the development of RNV and CNV, which BMCs are involved in [63]. MicroRNA-126 is one of the most extensively studied microRNAs known to be specifically expressed in ECs and HSCs [64, 65]. A downregulation of miR-126 has been observed in the retina from OIR mice as well as in hypoxic cultures of chorioretinal vessel ECs [66, 67]. Moreover, an overexpression of miR-126 was shown to reduce RNV by targeting VEGF, hypoxia-inducible factor- $1 \alpha$ and insulin-like growth factor [66].

VEGF, an important stimulator of neovascularization in several tissue including ocular neovascularization, is not only a target protein of several miRNAs such as miR-126 and miR-200b, but was also shown to induce expression of miRNAs like miR-132 in ECs [68-71]. Other miRNAs, including miRNA-31, -150 and -184 , which are decreased in RNV and CNV, were also shown to be involved in mediating neovascularization via their regulatory effect on different signaling proteins [72] (Table 1).

Despite more and more miRNAs that are now known to be expressed in vascular cells of ocular neovascularization, and the delineation of the roles of some of these miRNAs in BMCs, the specific expression and functionality of the majority of miRNAs in BMCs that contribute to ocular neovascularization have not been elucidated [16]. MiRNAs and their target genes involved in this event are yet to be discovered, and a growing body of evidence supporting the effect of miRNAs presents a potential strategy.

Our group has found previously that hypoxia significantly downregulated the expression of miR-188-5p and upregulated expressions of MMP-2 and -13 in BM-derived MSCs of mice (unpublished). To investigate the role of miR-188-5p, and its possible target genes that are related to BMCs in CNV, we propose that miR-188-5p may regulate degradation of ECM and PEDF in CNV, which in turn affects the proliferation, migration and apoptosis of vascular cells and fibrosis of CNV via regulation MMP-2 and -13 expressions. Further, the relation between miRNA and BMCs in CNV has been described (Fig. 2).

\section{Risk factors affecting bone marrow-derived cells' contribution to ocular neovascularization}

It is noteworthy that some risk factors for neovascular diseases such as aging and smoking tend to alter the BM microenvironment leading to exhaustion of BMCs and their contribution to the development of neovascularization. The effects of risk factors on ocular neovascularization, especially $\mathrm{CNV}$, have also been documented.

\section{Aging}

BMCs are affected by several risk factors like aging and are known to regulate the severity of ocular neovascularization formation. Aging BMCs are known to have agerelated dysfunction, which may be associated with a more intense response to pro-vascularization factors, an 
Table 1 Non-exhaustive list of microRNAs implicated in ocular neovascularization

\begin{tabular}{llll}
\hline MicroRNA & Target genes & Type of ocular neovascularization & References \\
\hline MiR-126 & VEGF, HIF-1a, IGF & RNV, CNV & {$[65-68]$} \\
MiR-200b & VEGF, OXR1 & RNV & {$[69,70]$} \\
MiR-31 & PDGF-B, HIF-1 $\alpha$ & RNV, CNV & {$[72]$} \\
MiR-150 & VEGF, PDGF-B & RNV, CNV & {$[72]$} \\
MiR-184 & Fzd4 & RNV, CNV & {$[72]$} \\
MiR-132 & Ras-GAP & CV & {$[71]$} \\
\hline
\end{tabular}

$M i R$ microRNA, $H I F-1 \alpha$ hypoxia-inducible factor-1 $\alpha, I G F$ insulin-like growth factor, $O X R 1$ oxidation resistance 1, PDGF-B platelet-derived growth factor-B, Fzd4 Frizzled4, Ras-GAP Ras-glyceraldehyde-3phosphate, $R N V$ retinal neovascularization, $C N V$ choroidal neovascularization, $C V$ corneal neovascularization

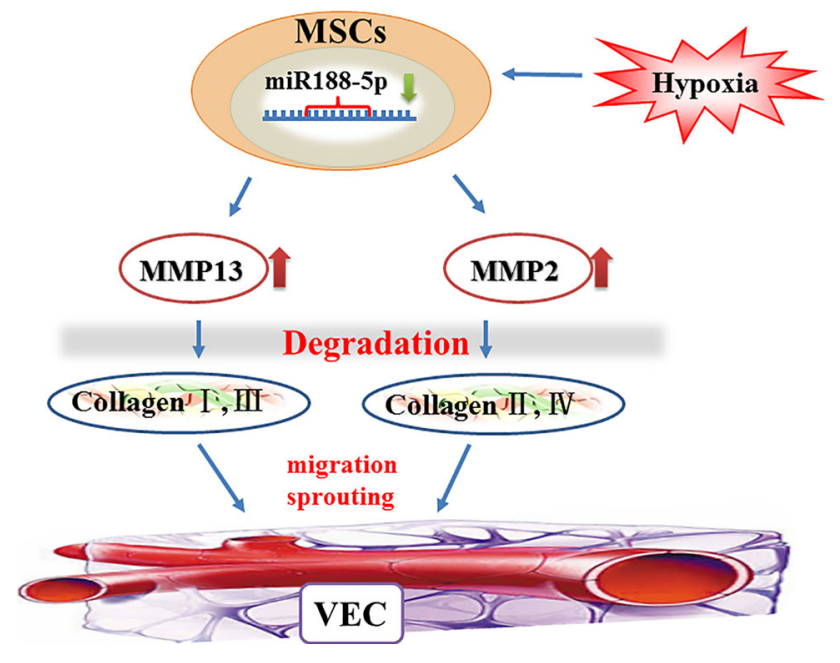

Fig. 2 Role of miR-188-5p in regulating the involvement of BMCs in the pathogenesis of choroidal neovascularization. We observed the relationship between miR-188-5p and MMP-2/13 in MSCs and demonstrated that overexpression of miR-188-5p attenuated the development of $\mathrm{CNV}$ as well as the effect of BMCs (unpublished data). These findings are consistent with the hypothesis that miR-188$5 \mathrm{p}$ may affect the proliferation, migration and apoptosis of vascular cells and fibrosis of $\mathrm{CNV}$ via regulating the MMP-2 and -13 expressions in BMCs, especially MSCs. BMCs bone marrow-derived cells, MSCs mesenchymal stem cells, MMP2/13 matrix metalloproteinase-2/13, VEC vascular endothelial cells

increased number of cells distributed to their corresponding positions and an altered direction of differentiation, thereby enhancing the severity of ocular neovascularization [1]. In their earlier studies of CNV, Espinosa-Heidmann et al. reported the effect of aging on neovascular remodeling [73, 74]. Recent work at our laboratory using in vivo bioluminescence imaging also suggested that aging BMCs aggravate the severity of CNV (unpublished). A study focusing on BMCs also demonstrated that the severity of CNV is more associated with the age of the cells within the BM, rather than with the age of the retina or choroid [75]. Another study demonstrated that HSCs showed more myelocytes in aged mice as compared to that in the young, which altered the balance of differentiation of HSCs toward lymphoid and myeloid lineage. The age-related function in BMCs appears to be related to the aberrant expression of some cytokines, growth factor receptors and cellular adhesion molecules [76]. Among them, aging appeared to cause Fasl gene change in eye, which induced the migration of pro-angiogenic M2 macrophages into the laser-induced lesions and increased pro-angiogenic cytokines promoting CNV [76, 77].

\section{Smoking}

Smoking, one of the most important risk factors for AMD, can serve to promote participation of the BMCs in the development of CNV. Nicotine, the major component of the particulate phase of cigarette smoke, was shown to induce an increase in the severity of CNV in a mouse model [74]. This finding is supported by another study in which nicotine-induced VEGF release, mediated through nicotinic acetylcholine receptor in VSMCs, was the likely underlying mechanism for the contribution of VEGF toward neovascularization in cigarette smokers. This process was shown to be mediated by epidermal growth factor receptor-extracellular signal-regulated kinase pathway [78]. Consistent with earlier studies, we have earlier shown that nicotine promotes recruitment and incorporation of BMCs into CNV and affects differentiation of BMCs in $\mathrm{CNV}$, which is partly due to upregulation of VEGF, bFGF and VCAM-1 [79]. The one common feature in these studies is the angiogenic stimulating factor, VEGF. This commonality suggests an indirect effect of nicotine on BMCs' contribution to CNV, possibly mediated via other factors. However, more mechanistic studies need to be conducted in the future.

\section{Hyperglycemia}

Hyperglycemia has also been recognized as a risk factor for ocular neovascularization and vision loss. DR is the most common cause of vision loss among 20- to 74-year-old 
Americans [80]. Our group focused on $\mathrm{CNV}$ has documented very high numbers of BMCs contributing to lesions in a mice model of $\mathrm{CNV}$ and demonstrated greater recruitment and incorporation of BMCs into $\mathrm{CNV}$ in mice with diabetes mellitus [7, 60]. We also found an increase in the ratio of BMCs expressing ECs marker or macrophage marker, besides upregulated expression of VEGF and SDF1 in CNV in vivo. In addition, human MSCs migration and expression of VEGF and SDF-1 in RPE cells appeared to increase on (in vitro) culture in high concentration of glucose [60]. This implies that hyperglycemia enhanced the expression of VEGF and SDF-1 in RPE cells, promoted recruitment and incorporation of BMCs, and affected differentiation of BMCs in CNV which appeared to increase the severity of CNV in diabetic mice. Hyperglycemia-induced oxidative stress is an upstream factor that promotes STAT3 activity, leading to the activation of VEGF transcription, which may indirectly accelerate the participation of BMCs and eventually exacerbate CNV [81].

\section{Research needs and future research priorities}

As discussed in this review, BMCs appear to play key roles in the development of ocular neovascularization with implications for the present anti-VEGF therapy as well as for the future antiangiogenic therapies. However, the regression of ocular neovascularization, such as RNV and $\mathrm{CNV}$, is rarely permanent and the regrowth of new vessels is observed in a few months without multiple applications of anti-VEGF agents [82]. To date, few studies have investigated the function and mechanisms underlying the role of BMCs in the recurrence of ocular neovascularization. The answers to this and other questions may help in formulating a combination of targeting BMCs therapy and current therapies to help optimize future antiangiogenic treatment.

In addition, the diagnosis of ocular neovascularization is often established only after formation of new vessels, or sometimes even with accompanying exudates and hemorrhage. It is now evident that BMCs arrive at the lesion prior to the formation of new vessels after their mobilization from $\mathrm{BM}$ and migration to the peripheral circulation. This makes it feasible to detect the activity of BMCs in the patients' blood before the solid mass formation. Sasahara et al. provided convincing evidence of the abnormal number and function of circulating BMCs in patients of $\mathrm{CNV}$, as being one of the systemic factors [28-30]. These studies led us to hypothesize whether BMCs and related cell factors could serve as potential markers to help in early detection of ocular neovascularization or recurrence of ocular neovascularization. Further prospective and longitudinal studies are still required.
Overall, it is still a largely unexplored field which can potentially help improve our understanding of the molecular mechanisms underlying the effect of BMCs in ocular neovascularization, and extend the clinical application of BMCs and their therapeutic use in the future.

\section{Summary}

Mounting evidence indicates that BMCs play a pivotal role in the pathogenesis of ocular neovascularization, which can be roughly divided into four steps, mobilization, migration, adhesion and differentiation. Each step is regulated by multiple factors. Cytokines mediating the BMCs' contribution, such as VEGF, G-CSF, EPO, SDF-1, TNF- $\alpha$, VCAM-1, ICAM-1, VE-cadherin, have been identified and represent potential novel targets for therapeutic application of BMCs. Furthermore, the identified risk factors for participation of BMCs in ocular neovascularization offer other potential targets for neovascularization interventions. A better understanding of the mechanisms underlying the involvement of BMCs in different kinds of ocular neovascularization will help to optimize ocular antiangiogenic therapy. Besides, this is an essential prerequisite for the use of BMCs as targets or vehicles for application not only to the eye but also to other parts of the body.

Acknowledgments This work was supported by the National Natural Scientific Research Foundation of China (No. 30672291, 81200708, 81070748, 81200151); the Scientific Research Foundation for the Outstanding Young Scientists (FMMU, 2012-2014; Xijing Hospital, 2014-2016). We appreciate Guorui Dou, Yan Cai, Yuanyuan Shi, Xia Li and other our team members' dedication to the accomplishment of this review.

Open Access This article is distributed under the terms of the Creative Commons Attribution 4.0 International License (http://crea tivecommons.org/licenses/by/4.0/), which permits unrestricted use, distribution, and reproduction in any medium, provided you give appropriate credit to the original author(s) and the source, provide a link to the Creative Commons license, and indicate if changes were made.

\section{References}

1. Hou HY, Liang HL, Wang YS (2011) Bone marrow-derived cells in neovascular age-related macular degeneration: contribution and potential application. Ophthalmic Res 45(1):1-4. doi:10. $1159 / 000313983$

2. Barnett JM, Penn JS, Jayagopal A (2013) Imaging of endothelial progenitor cell subpopulations in angiogenesis using quantum dot nanocrystals. Methods Mol Biol 1026:45-56. doi:10.1007/978-162703-468-5_4

3. Zhang SX, Ma JX (2007) Ocular neovascularization: implication of endogenous angiogenic inhibitors and potential therapy. Prog Retin Eye Res 26(1):1-37. doi:10.1016/j.preteyeres.2006.09.002 
4. Li Calzi S, Neu MB, Shaw LC, Kielczewski JL, Moldovan NI, Grant MB (2010) EPCs and pathological angiogenesis: when good cells go bad. Microvasc Res 79(3):207-216. doi:10.1016/j. mvr.2010.02.011

5. Patel-Hett S, D'Amore PA (2011) Signal transduction in vasculogenesis and developmental angiogenesis. Int $\mathrm{J}$ Dev Biol 55(4-5):353-363. doi:10.1387/ijdb.103213sp

6. Ozerdem U, Alitalo K, Salven P, Li A (2005) Contribution of bone marrow-derived pericyte precursor cells to corneal vasculogenesis. Invest Ophthalmol Vis Sci 46(10):3502-3506. doi:10. 1167/iovs.05-0309

7. Hou HY, Wang YS, Xu JF, Wang YC, Liu JP (2006) The dynamic conduct of bone marrow-derived cells in the choroidal neovascularization microenvironment. Curr Eye Res 31(12):1051-1061. doi:10.1080/02713680601100459

8. Shi YY, Wang YS, Zhang ZX, Cai Y, Zhou J, Hou HY, van Rooijen N (2011) Monocyte/macrophages promote vasculogenesis in choroidal neovascularization in mice by stimulating SDF-1 expression in RPE cells. Graefes Arch Clin Exp Ophthalmol 249(11):1667-1679. doi:10.1007/s00417-011-1699-4

9. Gimenez F, Suryawanshi A, Rouse BT (2013) Pathogenesis of herpes stromal keratitis-a focus on corneal neovascularization. Prog Retin Eye Res 33:1-9. doi:10.1016/j.preteyeres.2012.07.002

10. Kather JN, Kroll J (2014) Transgenic mouse models of corneal neovascularization: new perspectives for angiogenesis research. Invest Ophthalmol Vis Sci 55(11):7637-7651. doi:10.1167/iovs. 14- 15430

11. Bourghardt Peebo B, Fagerholm P, Traneus-Rockert C, Lagali $\mathrm{N}$ (2011) Time-lapse in vivo imaging of corneal angiogenesis: the role of inflammatory cells in capillary sprouting. Invest Ophthalmol Vis Sci 52(6):3060-3068. doi:10.1167/iovs.10-6101

12. Asahara $T$, Takahashi $T$, Masuda $H$, Kalka $C$, Chen D, Iwaguro H, Inai Y, Silver M, Isner JM (1999) VEGF contributes to postnatal neovascularization by mobilizing bone marrow-derived endothelial progenitor cells. EMBO J 18(14):3964-3972. doi:10. 1093/emboj/18.14.3964

13. Takahashi T, Kalka C, Masuda H, Chen D, Silver M, Kearney M, Magner M, Isner JM, Asahara T (1999) Ischemia- and cytokineinduced mobilization of bone marrow-derived endothelial progenitor cells for neovascularization. Nat Med 5(4):434-438. doi: $10.1038 / 7434$

14. Kirchmair R, Egger M, Walter DH, Eisterer W, Niederwanger A, Woell E, Nagl M, Pedrini M, Murayama T, Frauscher S, Hanley A, Silver M, Brodmann M, Sturm W, Fischer-Colbrie R, Losordo DW, Patsch JR, Schratzberger P (2004) Secretoneurin, an angiogenic neuropeptide, induces postnatal vasculogenesis. Circulation 110(9):1121-1127. doi:10.1161/01.CIR.0000139884. 81390.56

15. Han JK, Lee HS, Yang HM, Hur J, Jun SI, Kim JY, Cho CH, Koh GY, Peters JM, Park KW, Cho HJ, Lee HY, Kang HJ, Oh BH, Park YB, Kim HS (2008) Peroxisome proliferator-activated receptor-delta agonist enhances vasculogenesis by regulating endothelial progenitor cells through genomic and nongenomic activations of the phosphatidylinositol 3-kinase/Akt pathway. Circulation 118(10):1021-1033. doi:10.1161/CIRCULATIO NAHA.108.777169

16. Campochiaro PA (2013) Ocular neovascularization. J Mol Med (Berl) 91(3):311-321. doi:10.1007/s00109-013-0993-5

17. Grant MB, May WS, Caballero S, Brown GA, Guthrie SM, Mames RN, Byrne BJ, Vaught T, Spoerri PE, Peck AB, Scott EW (2002) Adult hematopoietic stem cells provide functional hemangioblast activity during retinal neovascularization. Nat Med 8(6):607-612. doi:10.1038/nm0602-607

18. Otani A, Kinder K, Ewalt K, Otero FJ, Schimmel P, Friedlander M (2002) Bone marrow-derived stem cells target retinal astrocytes and can promote or inhibit retinal angiogenesis. Nat Med 8(9):1004-1010. doi:10.1038/nm744

19. Shen J, Xie B, Dong A, Swaim M, Hackett SF, Campochiaro PA (2007) In vivo immunostaining demonstrates macrophages associate with growing and regressing vessels. Invest Ophthalmol Vis Sci 48(9):4335-4341. doi:10.1167/iovs.07-0113

20. Kramerov AA, Saghizadeh M, Caballero S, Shaw LC, Li Calzi S, Bretner M, Montenarh M, Pinna LA, Grant MB, Ljubimov AV (2008) Inhibition of protein kinase CK2 suppresses angiogenesis and hematopoietic stem cell recruitment to retinal neovascularization sites. Mol Cell Biochem 316(1-2):177-186. doi:10.1007/ s11010-008-9831-4

21. Shimada N, Ohno-Matsui K, Iseki S, Koike M, Uchiyama Y, Wang J, Yoshida T, Sato T, Peters C, Mochizuki M, Morita I (2010) Cathepsin L in bone marrow-derived cells is required for retinal and choroidal neovascularization. Am J Pathol 176(5):2571-2580. doi:10.2353/ajpath.2010.091027

22. Zou H, Otani A, Oishi A, Yodoi Y, Kameda T, Kojima H, Yoshimura N (2010) Bone marrow-derived cells are differentially involved in pathological and physiological retinal angiogenesis in mice. Biochem Biophys Res Commun 391(2):1268-1273. doi:10. 1016/j.bbrc.2009.12.057

23. Dong A, Shen J, Zeng M, Campochiaro PA (2011) Vascular celladhesion molecule-1 plays a central role in the proangiogenic effects of oxidative stress. Proc Natl Acad Sci USA 108(35):14614-14619. doi:10.1073/pnas.1012859108

24. Ishikawa K, Yoshida S, Nakao S, Sassa Y, Asato R, Kohno R, Arima M, Kita T, Yoshida A, Ohuchida K, Ishibashi T (2012) Bone marrow-derived monocyte lineage cells recruited by MIP1 beta promote physiological revascularization in mouse model of oxygen-induced retinopathy. Lab Invest 92(1):91-101. doi:10. 1038/labinvest.2011.141

25. Longeras R, Farjo K, Ihnat M, Ma JX (2012) A PEDF-derived peptide inhibits retinal neovascularization and blocks mobilization of bone marrow-derived endothelial progenitor cells. Exp Diabetes Res 2012:518426. doi:10.1155/2012/518426

26. Abu El-Asrar AM, Struyf S, Verbeke H, Van Damme J, Geboes K (2011) Circulating bone-marrow-derived endothelial precursor cells contribute to neovascularization in diabetic epiretinal membranes. Acta Ophthalmol 89(3):222-228. doi:10.1111/j.1755-3768.2009.01700.x

27. Sheridan CM, Rice D, Hiscott PS, Wong D, Kent DL (2006) The presence of AC133-positive cells suggests a possible role of endothelial progenitor cells in the formation of choroidal neovascularization. Invest Ophthalmol Vis Sci 47(4):1642-1645. doi:10.1167/iovs.05-0779

28. Sasahara M, Otani A, Yodoi Y, Gotoh N, Kameda T, Yoshimura N (2009) Circulating hematopoietic stem cells in patients with choroidal neovascularization secondary to pathologic myopia. Eye 23(3):718-726. doi:10.1038/eye.2008.192

29. Sasahara M, Otani A, Yodoi Y, Yoshimura N (2009) Circulating hematopoietic stem cells in patients with idiopathic choroidal neovascularization. Invest Ophthalmol Vis Sci 50(4):1575-1579. doi:10.1167/iovs.08-1900

30. Yodoi Y, Sasahara M, Kameda T, Yoshimura N, Otani A (2007) Circulating hematopoietic stem cells in patients with neovascular age-related macular degeneration. Invest Ophthalmol Vis Sci 48(12):5464-5472. doi:10.1167/iovs.07-0093

31. Espinosa-Heidmann DG, Caicedo A, Hernandez EP, Csaky KG, Cousins SW (2003) Bone marrow-derived progenitor cells contribute to experimental choroidal neovascularization. Invest Ophthalmol Vis Sci 44(11):4914-4919

32. Sengupta N, Caballero S, Mames RN, Butler JM, Scott EW, Grant MB (2003) The role of adult bone marrow-derived stem cells in choroidal neovascularization. Invest Ophthalmol Vis Sci 44(11):4908-4913 
33. Espinosa-Heidmann DG, Reinoso MA, Pina Y, Csaky KG, Caicedo A, Cousins SW (2005) Quantitative enumeration of vascular smooth muscle cells and endothelial cells derived from bone marrow precursors in experimental choroidal neovascularization. Exp Eye Res 80(3):369-378. doi:10.1016/j.exer.2004.10.005

34. Sengupta N, Caballero S, Mames RN, Timmers AM, Saban D, Grant MB (2005) Preventing stem cell incorporation into choroidal neovascularization by targeting homing and attachment factors. Invest Ophthalmol Vis Sci 46(1):343-348. doi:10.1167/ iovs.04-0153

35. Murayama T, Tepper OM, Silver M, Ma H, Losordo DW, Isner JM, Asahara T, Kalka C (2002) Determination of bone marrowderived endothelial progenitor cell significance in angiogenic growth factor-induced neovascularization in vivo. Exp Hematol 30(8):967-972

36. Li H, Wang Y, Cao F (2013) In vivo bioluminescence imaging monitoring of stem cells' participation in choroidal neovascularization. Ophthalmic Res 50(1):19-26. doi:10.1159/000348737

37. Hera R, Keramidas M, Peoc'h M, Mouillon M, Romanet JP, Feige JJ (2005) Expression of VEGF and angiopoietins in subfoveal membranes from patients with age-related macular degeneration. Am J Ophthalmol 139(4):589-596. doi:10.1016/j.ajo.2004.11.064

38. Spilsbury K, Garrett KL, Shen WY, Constable IJ, Rakoczy PE (2000) Overexpression of vascular endothelial growth factor (VEGF) in the retinal pigment epithelium leads to the development of choroidal neovascularization. Am $\mathrm{J}$ Pathol 157(1):135-144. doi:10.1016/S0002-9440(10)64525-7

39. Chang JH, Garg NK, Lunde E, Han KY, Jain S, Azar DT (2012) Corneal neovascularization: an anti-VEGF therapy review. Surv Ophthalmol 57(5):415-429. doi:10.1016/j.survophthal.2012.01. 007

40. Korf-Klingebiel M, Kempf T, Sauer T, Brinkmann E, Fischer P, Meyer GP, Ganser A, Drexler H, Wollert KC (2008) Bone marrow cells are a rich source of growth factors and cytokines: implications for cell therapy trials after myocardial infarction. Eur Heart J 29(23):2851-2858. doi:10.1093/eurheartj/ehn456

41. Lima e Silva R, Shen J, Hackett SF, Kachi S, Akiyama H, Kiuchi K, Yokoi K, Hatara MC, Lauer T, Aslam S, Gong YY, Xiao WH, Khu NH, Thut C, Campochiaro PA (2007) The SDF-1/CXCR4 ligand/receptor pair is an important contributor to several types of ocular neovascularization. FASEB J 21(12):3219-3230. doi:10. 1096/fj.06-7359com

42. Tilling L, Chowienczyk P, Clapp B (2009) Progenitors in motion: mechanisms of mobilization of endothelial progenitor cells. Br J Clin Pharmacol 68(4):484-492. doi:10.1111/j.1365-2125.2009. 03486.x

43. Ripa RS (2012) Granulocyte-colony stimulating factor therapy to induce neovascularization in ischemic heart disease. Dan Med J 59(3):B4411

44. Westenbrink BD, Lipsic E, van der Meer P, van der Harst P, Oeseburg H, Du Marchie Sarvaas GJ, Koster J, Voors AA, van Veldhuisen DJ, van Gilst WH, Schoemaker RG (2007) Erythropoietin improves cardiac function through endothelial progenitor cell and vascular endothelial growth factor mediated neovascularization. Eur Heart J 28(16):2018-2027. doi:10.1093/eurheartj/ ehm177

45. Chen J, Connor KM, Aderman CM, Smith LE (2008) Erythropoietin deficiency decreases vascular stability in mice. J Clin Invest 118(2):526-533. doi:10.1172/JCI33813

46. Hou HY, Liang HL, Wang YS, Zhang ZX, Wang BR, Shi YY, Dong X, Cai Y (2010) A therapeutic strategy for choroidal neovascularization based on recruitment of mesenchymal stem cells to the sites of lesions. Mol Ther 18(10):1837-1845. doi:10. 1038/mt.2010.144

47. Dorrell MI, Otani A, Aguilar E, Moreno SK, Friedlander M (2004) Adult bone marrow-derived stem cells use R-cadherin to target sites of neovascularization in the developing retina. Blood 103(9):3420-3427. doi:10.1182/blood-2003-09-3012

48. Zhang ZX, Wang YS, Shi YY, Hou HY, Zhang C, Cai Y, Dou GR, Yao LB, Li FY (2011) Hypoxia specific SDF-1 expression by retinal pigment epithelium initiates bone marrow-derived cells to participate in Choroidal neovascularization in a laser-induced mouse model. Curr Eye Res 36(9):838-849. doi:10.3109/ 02713683.2011.593107

49. Wang J, Ohno-Matsui K, Nakahama K, Okamoto A, Yoshida T, Shimada N, Mochizuki M, Morita I (2011) Amyloid beta enhances migration of endothelial progenitor cells by upregulating CX3CR1 in response to fractalkine, which may be associated with development of choroidal neovascularization. Arterioscler Thromb Vasc Biol 31(7):e11-e18. doi:10.1161/ATVBAHA.110. 215517

50. Saika S, Ikeda K, Yamanaka O, Flanders KC, Okada Y, Miyamoto T, Kitano A, Ooshima A, Nakajima Y, Ohnishi Y, Kao WW (2006) Loss of tumor necrosis factor alpha potentiates transforming growth factor beta-mediated pathogenic tissue response during wound healing. Am J Pathol 168(6):1848-1860

51. Semkova I, Muether PS, Kuebbeler M, Meyer KL, Kociok N, Joussen AM (2011) Recruitment of blood-derived inflammatory cells mediated via tumor necrosis factor-alpha receptor $1 \mathrm{~b}$ exacerbates choroidal neovascularization. Invest Ophthalmol Vis Sci 52(9):6101-6108. doi:10.1167/iovs.10-5996

52. Lecomte J, Louis K, Detry B, Blacher S, Lambert V, Bekaert S, Munaut C, Paupert J, Blaise P, Foidart JM, Rakic JM, Krane SM, Noel A (2011) Bone marrow-derived mesenchymal cells and MMP13 contribute to experimental choroidal neovascularization. Cell Mol Life Sci 68(4):677-686. doi:10.1007/s00018-010-0476-6

53. Ruster B, Gottig S, Ludwig RJ, Bistrian R, Muller S, Seifried E, Gille J, Henschler R (2006) Mesenchymal stem cells display coordinated rolling and adhesion behavior on endothelial cells. Blood 108(12):3938-3944. doi:10.1182/blood-2006-05-025098

54. Yin T, Ma X, Zhao L, Cheng K, Wang H (2008) Angiotensin II promotes NO production, inhibits apoptosis and enhances adhesion potential of bone marrow-derived endothelial progenitor cells. Cell Res 18(7):792-799. doi:10.1038/cr.2008.69

55. Otani A, Dorrell MI, Kinder K, Moreno SK, Nusinowitz S, Banin E, Heckenlively J, Friedlander M (2004) Rescue of retinal degeneration by intravitreally injected adult bone marrow-derived lineage-negative hematopoietic stem cells. J Clin Invest 114(6):765-774. doi:10.1172/JCI21686

56. Dou GR, Wang L, Wang YS, Han H (2012) Notch signaling in ocular vasculature development and diseases. Mol Med 18:47-55. doi:10.2119/molmed.2011.00256

57. Kwon SM, Alev C, Asahara T (2009) The role of notch signaling in endothelial progenitor cell biology. Trends Cardiovasc Med 19(5):170-173. doi:10.1016/j.tcm.2009.10.002

58. Kwon SM, Eguchi M, Wada M, Iwami Y, Hozumi K, Iwaguro H, Masuda H, Kawamoto A, Asahara T (2008) Specific Jagged-1 signal from bone marrow microenvironment is required for endothelial progenitor cell development for neovascularization. Circulation 118(2):157-165. doi:10.1161/CIRCULATIONAHA. 107.754978

59. Dou GR, Wang YC, Hu XB, Hou LH, Wang CM, Xu JF, Wang YS, Liang YM, Yao LB, Yang AG, Han H (2008) RBP-J, the transcription factor downstream of Notch receptors, is essential for the maintenance of vascular homeostasis in adult mice. FASEB J 22(5):1606-1617. doi:10.1096/fj.07-9998com

60. Cai Y, Li X, Wang YS, Shi YY, Ye Z, Yang GD, Dou GR, Hou HY, Yang N, Cao XR, Lu ZF (2014) Hyperglycemia promotes vasculogenesis in choroidal neovascularization in diabetic mice by stimulating VEGF and SDF-1 expression in retinal pigment epithelial cells. Exp Eye Res 123:87-96. doi:10.1016/j.exer.2014. 04.012 
61. Jost M, Maillard C, Lecomte J, Lambert V, Tjwa M, Blaise P, Alvarez Gonzalez ML, Bajou K, Blacher S, Motte P, Humblet C, Defresne MP, Thiry M, Frankenne F, Gothot A, Carmeliet P, Rakic JM, Foidart JM, Noel A (2007) Tumoral and choroidal vascularization: differential cellular mechanisms involving plasminogen activator inhibitor type I. Am J Pathol 171(4):1369-1380. doi:10.2353/ajpath.2007.070074

62. Lujambio A, Lowe SW (2012) The microcosmos of cancer. Nature 482(7385):347-355. doi:10.1038/nature10888

63. Wen Z, Zheng S, Zhou C, Yuan W, Wang J, Wang T (2012) Bone marrow mesenchymal stem cells for post-myocardial infarction cardiac repair: microRNAs as novel regulators. J Cell Mol Med 16(4):657-671. doi:10.1111/j.1582-4934.2011.01471.x

64. Mastropasqua R, Toto L, Cipollone F, Santovito D, Carpineto P, Mastropasqua L (2014) Role of microRNAs in the modulation of diabetic retinopathy. Prog Retin Eye Res 43:92-107. doi:10. 1016/j.preteyeres.2014.07.003

65. Wang S, Aurora AB, Johnson BA, Qi X, McAnally J, Hill JA, Richardson JA, Bassel-Duby R, Olson EN (2008) The endothelial-specific microRNA miR-126 governs vascular integrity and angiogenesis. Dev Cell 15(2):261-271. doi:10.1016/j.devcel. 2008.07.002

66. Bai Y, Bai X, Wang Z, Zhang X, Ruan C, Miao J (2011) MicroRNA-126 inhibits ischemia-induced retinal neovascularization via regulating angiogenic growth factors. Exp Mol Pathol 91(1):471-477. doi:10.1016/j.yexmp.2011.04.016

67. Ye P, Liu J, He F, Xu W, Yao K (2014) Hypoxia-induced deregulation of miR-126 and its regulative effect on VEGF and MMP-9 expression. Int J Med Sci 11(1):17-23. doi:10.7150/ijms. 7329

68. Fish JE, Santoro MM, Morton SU, Yu S, Yeh RF, Wythe JD, Ivey KN, Bruneau BG, Stainier DY, Srivastava D (2008) miR126 regulates angiogenic signaling and vascular integrity. Dev Cell 15(2):272-284. doi:10.1016/j.devcel.2008.07.008

69. McArthur K, Feng B, Wu Y, Chen S, Chakrabarti S (2011) MicroRNA-200b regulates vascular endothelial growth factormediated alterations in diabetic retinopathy. Diabetes 60(4):1314-1323. doi:10.2337/db10-1557

70. Murray AR, Chen Q, Takahashi Y, Zhou KK, Park K, Ma JX (2013) MicroRNA-200b downregulates oxidation resistance 1 (Oxr1) expression in the retina of type 1 diabetes model. Invest Ophthalmol Vis Sci 54(3):1689-1697. doi:10.1167/iovs.1210921

71. Mulik S, Xu J, Reddy PB, Rajasagi NK, Gimenez F, Sharma S, Lu PY, Rouse BT (2012) Role of miR-132 in angiogenesis after ocular infection with herpes simplex virus. Am J Pathol 181(2):525-534. doi:10.1016/j.ajpath.2012.04.014
72. Shen J, Yang X, Xie B, Chen Y, Swaim M, Hackett SF, Campochiaro PA (2008) MicroRNAs regulate ocular neovascularization. Mol Ther 16(7):1208-1216. doi:10.1038/mt.2008.104

73. Espinosa-Heidmann DG, Suner I, Hernandez EP, Frazier WD, Csaky KG, Cousins SW (2002) Age as an independent risk factor for severity of experimental choroidal neovascularization. Invest Ophthalmol Vis Sci 43(5):1567-1573

74. Suner IJ, Espinosa-Heidmann DG, Marin-Castano ME, Hernandez EP, Pereira-Simon S, Cousins SW (2004) Nicotine increases size and severity of experimental choroidal neovascularization. Invest Ophthalmol Vis Sci 45(1):311-317

75. Espinosa-Heidmann DG, Malek G, Mettu PS, Caicedo A, Saloupis P, Gach S, Dunnon AK, Hu P, Spiga MG, Cousins SW (2013) Bone marrow transplantation transfers age-related susceptibility to neovascular remodeling in murine laser-induced choroidal neovascularization. Invest Ophthalmol Vis Sci 54(12):7439-7449. doi:10.1167/iovs.13-12546

76. Zhao H, Roychoudhury J, Doggett TA, Apte RS, Ferguson TA (2013) Age-dependent changes in FasL (CD95L) modulate macrophage function in a model of age-related macular degeneration. Invest Ophthalmol Vis Sci 54(8):5321-5331. doi:10. 1167/iovs.13-12122

77. McMenamin PG (2013) Macrophages coming of age: their role in promoting CNV is modulated by FasL. Invest Ophthalmol Vis Sci 54(8):5332. doi:10.1167/iovs.13-12718

78. Kanda Y, Watanabe Y (2007) Nicotine-induced vascular endothelial growth factor release via the EGFR-ERK pathway in rat vascular smooth muscle cells. Life Sci 80(15):1409-1414. doi:10.1016/j.lfs.2006.12.033

79. Hou HY, Wang YS, Xu JF, Wang BR (2008) Nicotine promotes contribution of bone marrow-derived cells to experimental choroidal neovascularization in mice. Exp Eye Res 86(6):983-990. doi:10.1016/j.exer.2008.03.018

80. Lee P, Wang CC, Adamis AP (1998) Ocular neovascularization: an epidemiologic review. Surv Ophthalmol 43(3):245-269

81. Li X, Cai Y, Wang YS, Shi YY, Hou W, Xu CS, Wang HY, Ye Z, Yao LB, Zhang J (2012) Hyperglycaemia exacerbates choroidal neovascularisation in mice via the oxidative stress-induced activation of STAT3 signalling in RPE cells. PLoS ONE 7(10):e47600. doi:10.1371/journal.pone.0047600

82. Ahn SJ, Park KH, Woo SJ (2015) Subfoveal choroidal thickness changes following anti-vascular endothelial growth factor therapy in myopic choroidal neovascularization. Invest Ophthalmol Vis Sci 56(10):5794-5800. doi:10.1167/iovs.14-16006 